Journal of Clinical Investigation

Vol. 41, No. 10, 1962

\title{
INTERRELATION OF URIC ACID AND ETHANOL METABOLISM IN MAN *
}

\author{
By CHARLES S. LIEBER, DON P. JONES, MONTY S. LOSOWSKY, $\dagger$ AND \\ CHARLES S. DAVIDSON
}

\author{
(From the Thorndike Memorial Laboratory, and the Second and Fourth [Harvard] Medical \\ Services, Boston City Hospital, Boston, Mass.)
}

(Submitted for publication April 17, 1962 ; accepted June 14, 1962)

Traditionally, the drinking of large amounts of alcoholic beverages has been considered a common predisposing or precipitating cause of gout (1). Thus far, however, the possibility of a relationship between ethanol and urate metabolism does not seem to have been investigated. In an attempt to evaluate a possible effect of ethanol on uric acid metabolism, we have studied serum uric acid levels in patients intoxicated with ethanol. Having observed that ethanol leads to an elevation of serum uric acid concentration, we investigated the mechanisms of this effect.

\section{MATERIALS AND METHODS}

Subjects. Studies were conducted in 22 subjects, 31 to 67 years old, 19 males and 3 females (Subjects 4, 7, 19). None had gout or any known cause of secondary hyperuricemia. Renal function was normal as judged by blood urea concentration and urinary sediment, there was no major hematological abnormality, and all except Subject 8 were afebrile. Although all except Subject 14 admitted considerable ethanol intake in the past, at the time of the study none showed clinical or laboratory evidence of liver disease except Subjects 1, 4, and 8, who had compensated hepatic cirrhosis. Subject 14 suffered from chronic idiopathic adrenal insufficiency and was being treated with desoxycorticosterone acetate (DOCA) at the time of the study.

Studies in intoxicated patients. Sixteen patients were studied when admitted to the hospital acutely intoxicated with various alcoholic beverages. Venous blood was drawn for chemical determinations at the time of admission and at intervals thereafter. In each patient, the final serum uric acid concentration was compared with the initial value. The mean of the individual differences was calculated and its degree of significance tested by the $t$ test (2).

* Work supported in part by the U. S. Army Medical Research and Development Command, Department of the Army, contract DA-49-193-MD-2013, and by a grant from the Nutrition Foundation, Inc., N. Y.; included in abstract form in J. clin. Invest. 1962, 41, 1380.

$\dagger$ Recipient of a Wellcome Research Travel Grant.
Administration of ethanol. Seven subjects, 4, 13, 14, $15,16,17$, and 22 , were investigated on the Thorndike Metabolic Ward before, during, and after ethanol administration. The amount of ethanol administered is indicated individually with the results observed in each of these patients.

A. Intravenous infusions. In three subjects, 13, 14, and 15 , ethanol was given after an overnight fast as a continuous infusion of a 15 per cent by volume solution in isotonic saline. In Subject 15, this was preceded by a $21 / 2$-hour control period during which saline solution was administered. In Subject 13, a control test with isotonic saline solution alone was done on another day.

B. Oral tests. After an overnight fast, Subjects 4, 16, 17 , and 22 were studied for a $21 / 2$-hour control period during which water flavored with grapefruit juice was administered orally to compensate for urinary water losses. Thereafter, in addition to the water, the patients were given ethanol in concentrations varying from 10 to 35 per cent by volume. This was administered every half hour for the subsequent 8 to 10 hours, without food intake, and later, every 4 hours, in addition to diet, for approximately a day.

In addition to his intravenous study, Subject 15 was given a 3-day course of oral ethanol preceded and followed by control periods of approximately 2 days' duration. Ethanol was administered every 4 hours as a 15 per cent solution in water flavored with grapefruit juice. A mixture of grapefruit juice and water alone was administered during the control periods.

Subject 17 was submitted to 3 additional 1-day studies. In place of ethanol, he was given isocaloric amounts of glucose once and neutralized sodium lactate ${ }^{1}$ at $300 \mathrm{mg}$ per $\mathrm{ml}$ twice.

Techniques. Subjects $4,15,16,17$, and 22 were kept on a constant purine diet throughout the entire tests. In Subjects 4, 15 (intravenous test), 16, 17, and 22, blood was collected through an indwelling Cournand needle in the brachial artery during the first 10 to 12 hours of the test. Thereafter, and in all other subjects, blood samples were taken from a brachial vein with special care to avoid stasis and to have the patient resting prior to the blood sampling.

Serum uric acid was determined by the method of Liddle, Seegmiller, and Laster (3). The difference between duplicates was usually less than 3 but occasionally

${ }^{1}$ Mallinckrodt U. S. P. 
as much as $\mathbf{5}$ per cent. Measurements were also done of serum ethanol (4) and serum creatinine (5). Glucose (6), hematocrit, and lactate were determined on whole blood. For lactate determination, approximately $1 \mathrm{ml}$ of blood was transferred within 5 to 10 seconds after withdrawal to a weighed glass-stoppered tube containing 9 $\mathrm{ml}$ of 10 per cent (wt/vol) trichloracetic acid in $0.5 \mathrm{~N}$ $\mathrm{HCl}$ at $0^{\circ} \mathrm{C}$ and shaken vigorously at once. After reweighing and centrifugation, lactate was determined on the supernatant fluid by the method of Barker and Summerson (7). In our laboratory, the mean arterial lactate level in 18 normal fasting and resting subjects was 7.1 mg per cent, with SD of $1.8 \mathrm{mg}$ per cent. In Subjects 4, 17 , and 22, urine samples were collected through an indwelling Foley catheter, and measurements were made of total volume, uric acid (3), creatinine (5), and $\mathrm{pH}$, with an $\mathrm{H}-2$ Beckman $\mathrm{pH}$ meter. All determinations were done in duplicate.

\section{RESULTS}

1. Serum uric acid and blood lactate in spontaneously and acutely intoxicated subjects. Figure 1 shows the serum uric acid concentrations of 12 subjects when acutely intoxicated and at various intervals thereafter.

In Subjects 1 to 5 when intoxicated, serum uric acid varied from 9.7 to $11.5 \mathrm{mg}$ per cent, which is

\section{SERUM URIC ACID AFTER ACUTE ALCOHOLISM}

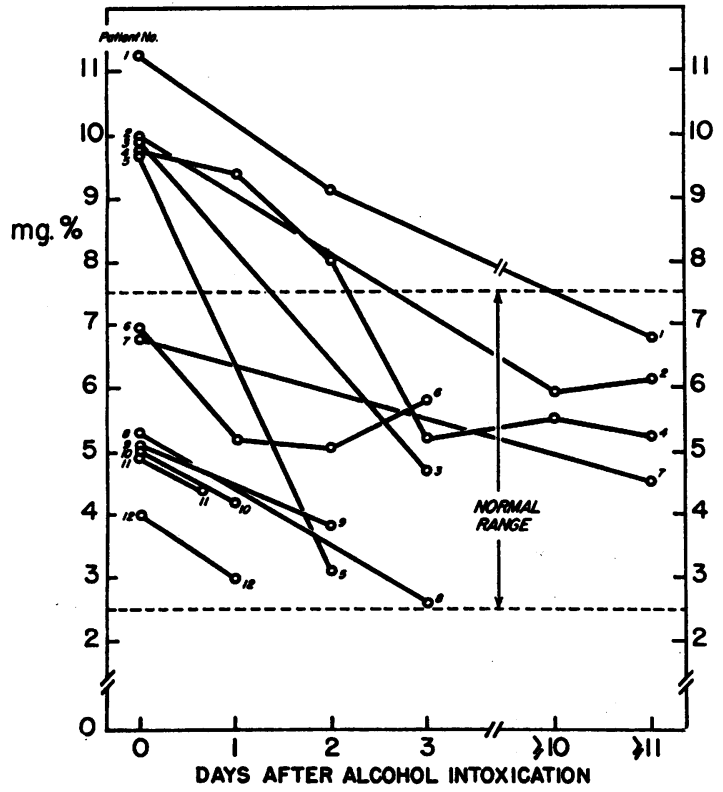

Fig. 1. Serum uric acid concentrations in 12 subJECTS WHEN ACUTELY INTOXICATED AND AT VARIOUS INTERVALS THEREAFTER, WITH THE NORMAL RANGE (MEAN \pm $2 \mathrm{SD})$.
TABLE I

Blood lactate in acute alcoholics

\begin{tabular}{|c|c|c|c|c|}
\hline \multirow[t]{2}{*}{ Subject } & \multicolumn{2}{|c|}{ Serum alcohol } & \multicolumn{2}{|c|}{ Blood lactate } \\
\hline & & & drunk & sober \\
\hline \multirow{10}{*}{$\begin{array}{r}4 \\
6 \\
8 \\
11 \\
18 \\
19 \\
20 \\
21\end{array}$} & & $m g \%$ & \multicolumn{2}{|c|}{$m g \%$} \\
\hline & & 325 & 36.0 & 7.5 \\
\hline & & 320 & 24.5 & 8.0 \\
\hline & & 265 & 16.5 & \\
\hline & & 400 & 17.0 & \\
\hline & & 290 & 21.5 & \\
\hline & & 262 & 13.0 & \\
\hline & & 350 & 34.5 & \\
\hline & & 278 & 15.5 & 9.0 \\
\hline & Mean & 311 & 22.3 & \\
\hline
\end{tabular}

well beyond the upper limit of normal of $7.5 \mathrm{mg}$ per cent for the enzymatic spectrophotometric method (8). In all subjects, serum uric acid returned to within the normal range on recovery. In Subjects 6 to 12, serum uric acid values were initially within normal limits, but in all these as well as in Subjects 1 to 5, the values were higher in the acute stage of intoxication than thereafter. The average decrease in the 12 subjects was 38 per cent, $\mathrm{p}<0.001$.

Measurements of serum ethanol and lactate were performed in four of the subjects above, 4 , 6,8 , and 11 , and in 4 additional acute alcoholics
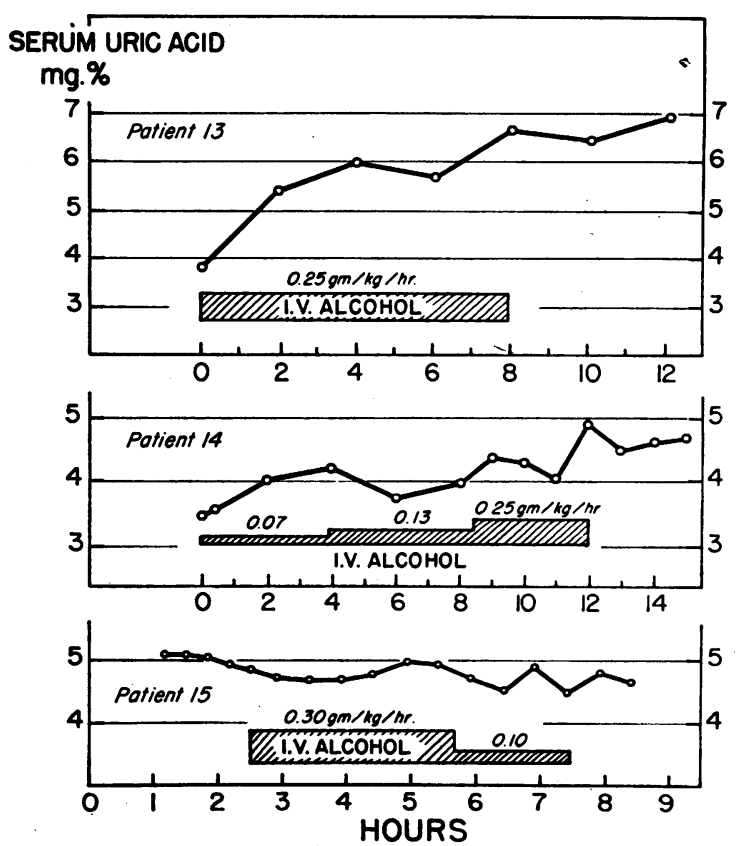

Fig. 2. EFfect of INTRAVENOUS ETHANOL ON SERUM URIC ACID CONCENTRATIONS. 
(Table I). Serum ethanol averaged $311 \mathrm{mg}$ per cent. The blood lactate concentration was elevated in each of the eight subjects. In three, in whom measurements were repeated when sober, values had returned to normal.

2. The effect of ethanol on serum uric acid concentration. In Subjects 13 and 14, intravenous administration of ethanol resulted in serum ethanol levels of 225 and $200 \mathrm{mg}$ per cent, respectively, with a concomitant increase of serum uric acid in Subject 13, and possibly also in Subject 14 (Figure 2). The rise in serum uric acid seemed to continue in both subjects beyond the actual period of ethanol administration, while serum ethanol levels remained above 200 and $145 \mathrm{mg}$ per cent, respectively. On another day, Subject 13
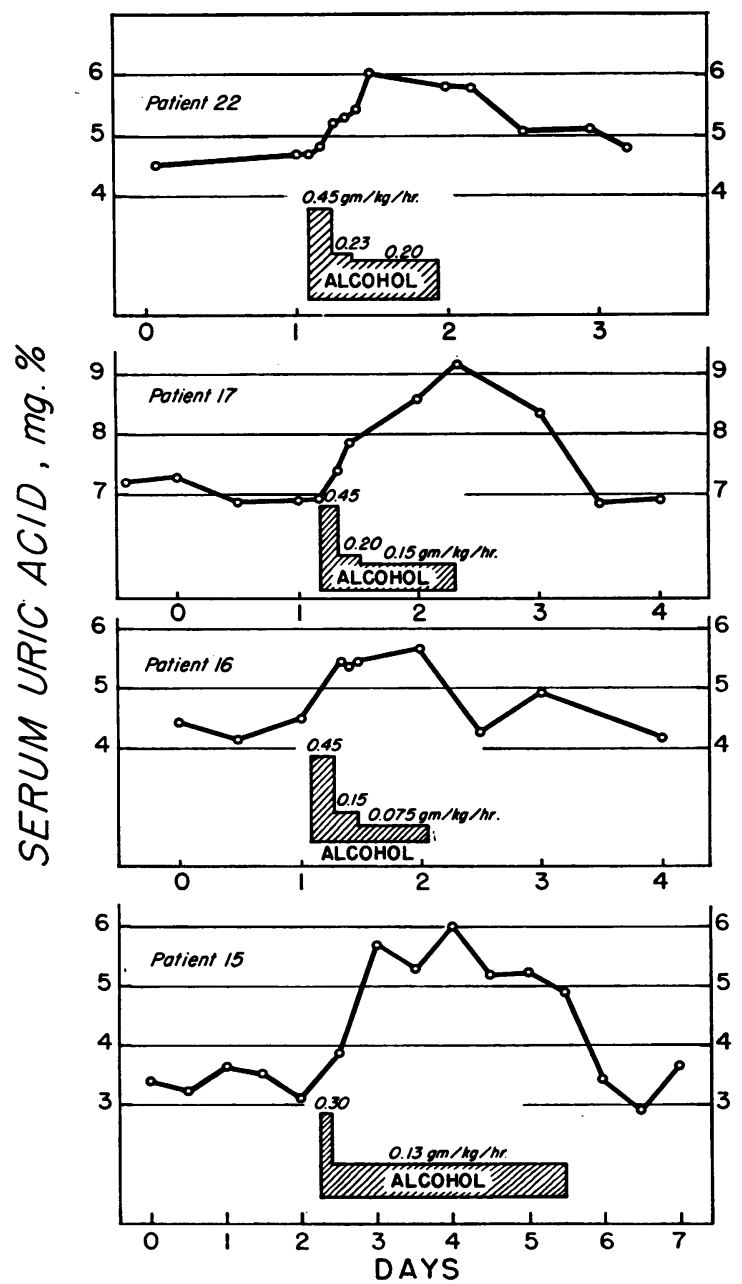

Fig. 3. EFFECT OF ORAL ETHANOL ON SERUM URIC ACID concentrations in SUbjects 15, 16, 17, and 22.

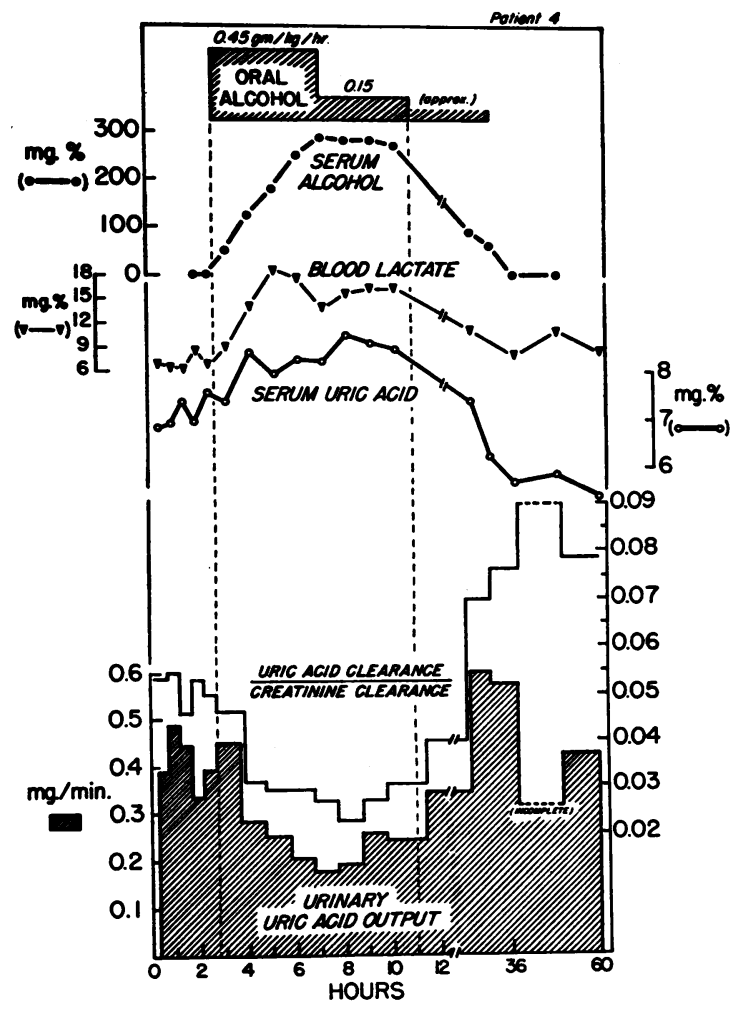

Fig. 4. Blood AND URINE STUdies WITH ORAL ETHANOL in Subject 4.

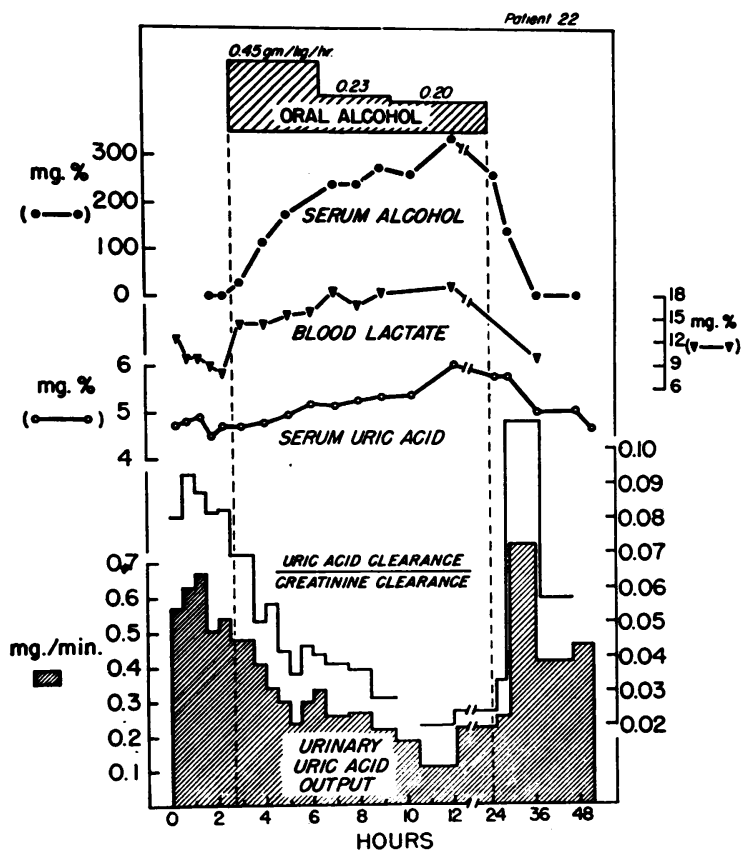

Fig. 5. BLOOD AND URINE STUdies With ORAL ETHANOL in Subject 22. 
was given intravenous saline solution without ethanol, and no change in serum uric acid was observed. In Subject 15 (see Figure 2), no rise of serum uric acid was observed with intravenous ethanol, but the serum ethanol level surprisingly never rose above $140 \mathrm{mg}$ per cent. When this subject was given a 30 per cent larger maintenance dose of ethanol orally for a much longer period, 3 days, he did show a rise in serum uric acid (Figure 3). Serum ethanol levels were not determined during this oral test.

In all subjects given ethanol orally-Subjects $4,15,16,17$, and 22-serum uric acid increased, and returned to control values when ethanol was withdrawn (Figures 3, 4). Signs of moderate intoxication, such as euphoria, were observed in all subjects given ethanol.

3. Urinary studies. Urinary studies were conducted in three of the patients given ethanol orally (Figures 4-6). In all three, serum ethanol concentrations rose above $200 \mathrm{mg}$ per cent, and blood lactate increased to 16 to $22 \mathrm{mg}$ per cent.

The rise in serum uric acid concentrations was accompanied in all three subjects by a decrease in urinary uric acid output to about 20 to 50 per cent

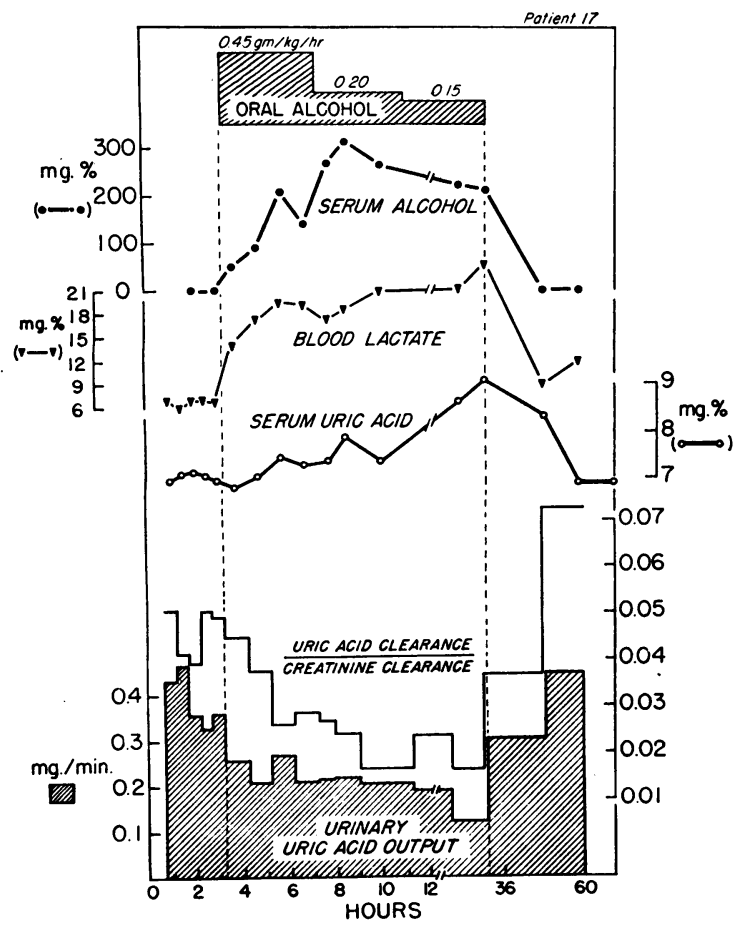

Fig. 6. Blood and URINe studies with oral ethanol in Subject 17.

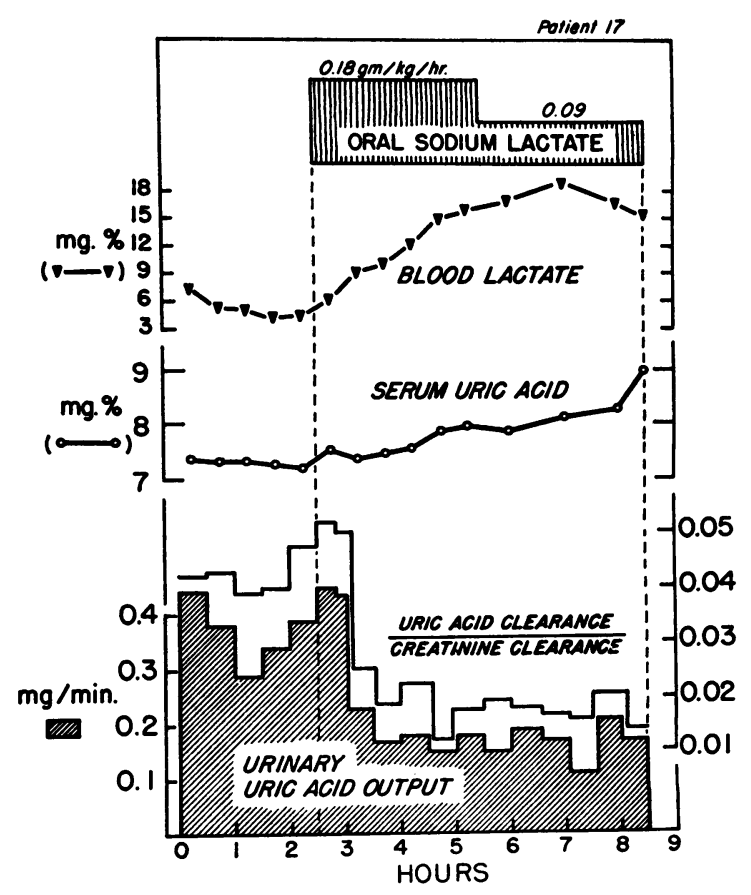

Fig. 7. BLOOD AND URINE STUdies With ORAL SODIUM lactate in Subject 17.

of the control values. The hematocrit, blood glucose, and endogenous creatinine clearance remained unchanged during the entire procedure, and the ratio of uric acid clearance to creatinine clearance paralleled urinary uric acid output (see Figures 4-6). After cessation of ethanol intake, urinary uric acid outputs returned to control levels.

In Subject 17, on another day, a control test was done with oral administration of isocaloric amounts of glucose instead of ethanol. Blood glucose rose from 86 to $230 \mathrm{mg}$ per cent, but blood lactate, serum uric acid, urinary uric acid output, and creatinine clearance did not change significantly.

In the same patient, sodium lactate was given orally on a different day. As indicated in Figure 7 , blood lactate and serum uric acid increased, while urinary uric acid output decreased. Creatinine clearance remained unchanged and the ratio of uric acid clearance to creatinine clearance paralleled the decrease in urinary uric acid output. Similar results had been observed during a previous lactate test performed in the same patient over a shorter period.

Urinary $\mathrm{pH}$ was measured in Subjects 4,17 , 


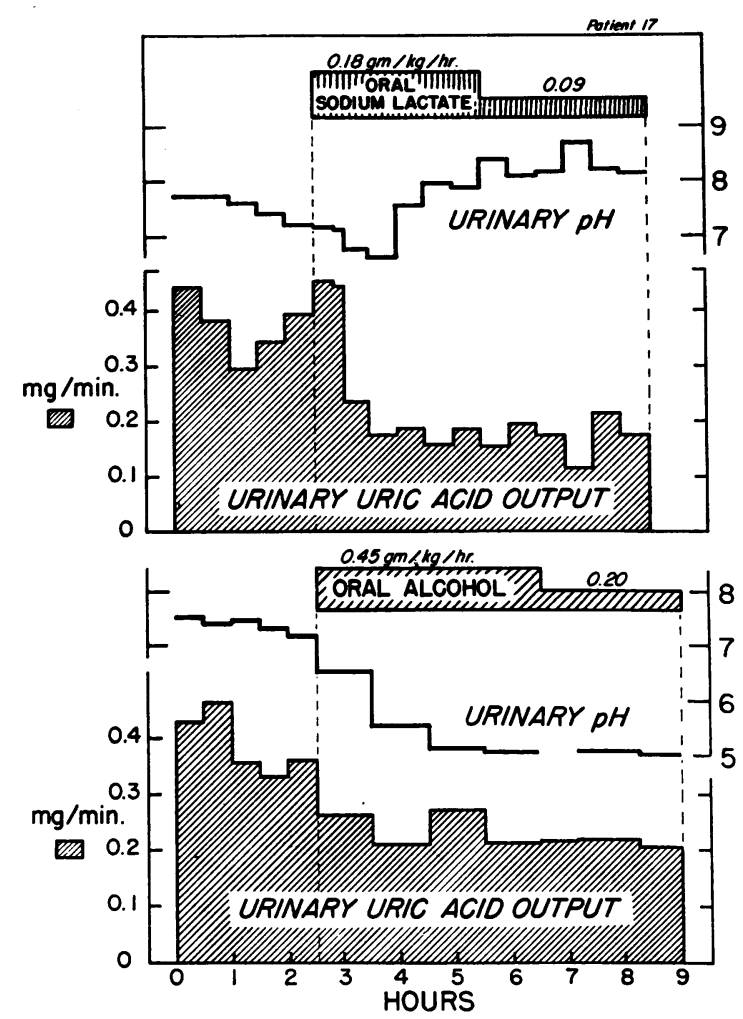

Fig. 8. EFfects of lactate and EThanol on URINARY pH ANd URIC acid outputs in Subject 17.

and 22. In Subject 22, the urinary $\mathrm{pH}$ was acid during the control period, and no significant change was observed after ethanol administration. Subjects 4 and 17, however, had an alkaline urine during the control period, and in both cases ethanol administration was accompanied by acidification of the urine, as shown in Figure 8 for Subject 17. When sodium lactate was administered to him, urinary $\mathrm{pH}$ changed in the opposite direction and became markedly alkaline (see Figure 8 ).

\section{DISCUSSION}

The data presented in Figure 1 indicate that in subjects who had taken intoxicating amounts of alcoholic beverages, serum uric acid concentrations were significantly higher during the stage of acute inebriation than after recovery. Furthermore, in 5 out of 12 subjects, the initial serum uric acid levels were well beyond the upper limit of normal, although none of the subjects had a known cause of hyperuricemia. In all subjects, the values returned to normal on recovery. These observations suggest a relationship between uric acid and ethanol, but they do not, by themselves, rule out the possibility that the observed hyperuricemia could be due to some factor other than ethanol, for instance, another component of the alcoholic beverages. That the observed hyperuricemia, however, is due, at least in part, to ethanol itself is suggested by the observation that administration of pure ethanol resulted in an increase of serum uric acid concentration in 7 subjects (see Figures 2-4). This rise in serum uric acid produced by ethanol was accompanied by a decrease in urinary uric acid output (see Figures 4-6) without alteration in glomerular filtration rate, as indicated by endogenous creatinine clearances. In all patients in whom urinary studies were done, calculation of the deficit in urinary uric acid excretion represented in Figures 4 to 6 shows that this could account for the rise in serum uric acid observed in these patients, if we assume that they had a uric acid pool which was stable and of normal size, and that the equilibration between serum uric acid and the body's uric acid pool may normally take up to 12 hours or more (9).

In experimental animals, it has been shown that the oxidation of alcohol to acetaldehyde, which generates reduced diphosphopyridine nucleotide (DPNH) $(10)$, is in part coupled with the reduction of pyruvic acid to lactic acid (11-13), according to the reactions indicated in Figure 9. It is possible that a similar mechanism is at least partly responsible for the rise in blood lactate which has been observed in man after ethanol administration (14-17), since in similar experimental conditions an increase in the lactate: pyruvate ratio has been observed in arterial (18) and hepatic venous $(18,19)$ blood. In the present study, however, the cause of the rise in blood lactate was not specifically investigated, and theo-

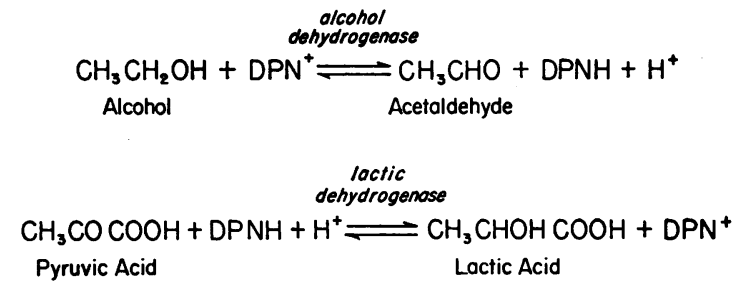

Fig. 9. Coupling of the oxidation of ethanol and THE REDUCTION OF PYRUVIC ACID. 
retically, other mechanisms such as increased muscular activity (20-22) or hyperventilation (23) might play a role, although clinically these were not evident. Furthermore, the high blood lactate of hyperventilation occurs under conditions-alkalosis and unchanged lactate: pyruvate ratio (23) -different from those after ethanol administration, which produces acidosis (24) and, as discussed above, a rise in the lactate: pyruvate ratio. The subjects given ethanol in the present study had no signs of peripheral circulatory failure, but oxygen saturation was not measured, and thus anoxemia, although unlikely, cannot formally be ruled out as a cause for lactate accumulation.

In various conditions accompanied by an elevated blood lactate, such as exercise $(20,21)$, toxemia of pregnancy (25), and glycogen storage disease (26), decreases in urinary urate excretion and high serum uric acid levels have been described. These effects have been attributed to the rise in blood lactate, since lactate administration is known to decrease urinary uric acid excretion (27-29). Thus, it appears reasonable to assume that the rise in serum uric acid concentration and the concomitant decrease in urinary uric acid output, which we observed in patients given ethanol, resulted, at least in part, from the rise in blood lactate. This concept is supported by the observation that the ingestion of sodium lactate by one subject formerly given ethanol led to increases in blood lactate concentrations (possibly due to alkalosis as well as to the administered lactate as such), decreases in urine urate excretion, and increases in serum urate similar to those after ethanol (see Figures 6, 7).

In the present and in previous studies investigating the effect of lactate on renal uric acid excretion $(28,29)$, the $R$, racemic, form has been administered, but in mammalian species, L-lactate is preferentially metabolized $(30,31)$. Since the chemical method used (7) measures both D- and L-lactate, and since the relative proportions of the two isomers in the blood and their respective effects on uric acid excretion are unknown, it is difficult to relate blood lactate values to urinary urate excretion quantitatively. Qualitatively, however, it seems well established that a reduction in urinary uric acid excretion accompanies an increase in blood lactate, whether the latter is achieved by the administration of $\mathrm{R}$ lactate (28, 29 , Figure 7 ) or whether it results from metabolic causes, such as exercise $(20,21)$, toxemia of pregnancy (25), glycogen storage disease (26), or ethanol, as shown in the present study.

The mechanism by which lactate affects urinary uric acid excretion is unknown. Theoretically, the dissociation of a weak acid, such as uric acid, can be expected to decrease in acid urine, and since ethanol administration may be accompanied by acidification of the urine, this could result in enhanced reabsorption of uric acid by back diffusion of the un-ionized form. In two out of three patients given ethanol, the rise in blood lactate was accompanied by urinary acidification, as had been described before $(24,32)$. Urinary acidification, however, does not appear to be primarily responsible for the decrease in urinary uric acid output, since, in confirmation of previous findings (33), in the patient given sodium lactate, the urine became strongly alkaline; nevertheless, lactate administration was accompanied by a decrease in urinary uric acid output and a rise in serum uric acid similar to those observed in the same patient on alcohol administration, although the urine $\mathrm{pH}$ was about 5 in the latter condition (see Figures 6-8). Furthermore, changes in urinary $\mathrm{pH}$ do not, in general, markedly affect urinary uric acid excretion (34).

In eight patients spontaneously intoxicated with various alcoholic beverages (Table I), high blood lactate levels were observed, confirming previous findings (14). These values were as high as, or even higher than, those found in the patients given ethanol. As discussed above, similar lactate levels are known to decrease urinary uric acid output. Therefore, it is reasonable to assume that the hyperuricemia observed in patients spontaneously intoxicated with alcoholic beverages (see Figure 1) is due, at least in part, to the following sequence of events: oxidation of ethanol to acetaldehyde generates DPNH, which reduces pyruvate to lactate; the resulting rise in blood lactate decreases urinary uric acid output, which leads to an increase in serum uric acid concentration.

The role of this effect of ethanol on uric acid metabolism as a predisposing or precipitating factor for arthritic attacks remains to be evaluated in patients with gout. 


\section{SUMMARY}

1. Serum uric acid concentration was measured in twelve subjects acutely intoxicated with alcoholic beverages. During recovery, uric acid concentrations decreased in all. In five, the initial concentration was above normal, but returned to within the normal range.

2. In seven subjects, oral or intravenous administration of ethanol resulted in a rise of serum uric acid.

3. In three subjects in whom urinary studies were done, the rise in serum uric acid was accompanied by a decrease of urinary uric acid excretion, without change in creatinine clearance. This effect did not primarily result from urinary $\mathrm{pH}$ changes.

4. Lactate administration produced a similar decrease in urate excretion, suggesting that the observed reduction in urinary uric acid output and the concomitant rise in serum uric acid were due to the increase in blood lactate produced by the oxidation of ethanol.

\section{ACKNOWLEDGMENTS}

The authors are grateful to Dr. Norbert Freinkel for allowing them to study two patients under his care, to Misses L. M. DeCarli, E. Doyle, and E. Greene for expert technical assistance, to Mrs. C. Jewell for drawings and calculations, and to Mrs. W. Stocker for preparation of the diets.

\section{REFERENCES}

1. Garrod, A. B. A Treatise on Gout and Rheumatic Gout, 3rd ed. London, Longmans, Green, 1876, p. 217.

2. Snedecor, G. W. Statistical Method, 4th ed. Ames, Iowa, Iowa State College, 1948.

3. Liddle, L., Seegmiller, J. E., and Laster, L. The enzymatic spectrophotometric method for determination of uric acid. J. Lab. clin. Med. 1959, 54, 903 .

4. Newman, E. J., and Newman, H. W. A microdiffusion method for alcohol determination. Stanf. med. Bull. 1953, 11, 96.

5. Hare, R. S. Endogenous creatinine in serum and urine. Proc. Soc. exp. Biol. (N. Y.) 1950, 74, 148.

6. Nelson, N. A photometric adaptation of the Somogyi method for the determination of glucose. J. biol. Chem. 1944, 153, 375.

7. Barker, S. B., and Summerson, W. H. The colorimetric determination of lactic acid in biological material. J. biol. Chem. 1941, 138, 535.

8. Gjфrup, S., Poulsen, H., and Prætorius, E. The uric acid concentration in serum determined by enzymatic spectrophotometry. Scand. J. clin. I.ab. Invest. 1955, 7, 201.

9. Sørensen, L. B. The elimination of uric acid in manl. Scand. J. clin. Lab. Invest. 1960, 12, Suppl. 54, 109.

10. Westheimer, F. H., Fisher, H. F., Conn, E. E., and Vennesland, B. The enzymatic transfer of hydrogen from alcohol to DPN. J. Amer. chem. Soc. 1951, 73, 2403.

11. Leloir, L. F., and Muñoz, J. M. Ethyl alcohol metabolism in animal tissues. Biochem. J. 1938, 32, 299.

12. Westerfeld, W. W., Stotz, E., and Berg, R. L. The coupled oxidation-reduction of alcohol and pyruvate in vivo. J. biol. Chem. 1943, 149, 237.

13. Lundquist, F., Fugmann, U., Kläning, E., and Rasmussen, $H$. The metabolism of acetaldehyde in mammalian tissues. Reactions in rat-liver suspensions under anaerobic conditions. Biochem. J. 1959, 72, 409.

14. Himwich, H. E., Nahum, L. H., Rakieten, N., Fazikas, J. F., Du Bois, D., and Gildea, E. F. The metabolism of alcohol. J. Amer. med. Ass. 1933, 100, 651.

15. Nicholson, W. M., and Taylor, H. M. The effect of alcohol on the water and electrolyte balance in man. J. clin. Invest. 1938, 17, 279.

16. Mendeloff, A. I. Effect of intravenous infusions of ethanol upon estimated hepatic blood flow in man. J. clin. Invest. 1954, 33, 1298.

17. Lieber, C. S., Leevy, C. M., Stein, S. W., George, W. S., Cherrick, G. R., Abelmann, W. H., and Davidson, C. S. Effect of ethanol on plasma free fatty acids in man. J. Lab. clin. Med. 1962, 59, 826.

18. Lieber, C. S. Unpublished observations.

19. Seligson, D., Stone, H. H., and Nemir, P., Jr. The metabolism of ethanol in man. Surg. Forum 1959, 9, 85.

20. Quick, A. J. The effect of exercise on the excretion of uric acid, with a note on the influence of benzoic acid on uric acid elimination in liver diseases. J. biol. Chem. 1935, 110, 107.

21. Nichols, J., Miller, A. T., Jr., and Hiatt, E. P. Influence of muscular exercise on uric acid excretion in man. J. appl. Physiol. 1951, 3, 501.

22. Huckabee, W. E. Relationships of pyruvate and lactate during anaerobic metabolism. II. Exercise and formation of $\mathrm{O}_{2}$-debt. J. clin. Invest. 1958, 37, 255.

23. Huckabee, W. E. Relationships of pyruvate and lactate during anaerobic metabolism. I. Effects of infusion of pyruvate or glucose and of hyperventilation. J. clin. Invest. 1958, 37, 244.

24. Rubini, M. E., Kleeman, C. R., and Lamdin, E. Studies on alcohol diuresis. I. The effect of ethyl alcohol ingestion on water, electrolyte and acidbase metabolism. J. clin. Invest. 1955, 34, 439.

25. Handler, J. S. The role of lactic acid in the reduced 
excretion of uric acid in toxemia of pregnancy. J. clin. Invest. 1960, 39, 1526.

26. Jeandet, J., and Lestradet, H. L'hyperlactacidémie, cause probable de l'hyperuricémie dans la glycogenose hépatique. Rev. franç. Et. clin. biol. 1961, $6,71$.

27. Gibson, H. V., and Doisy, E. A. A note on the effect of some organic acids upon the uric acid excretion of man. J. biol. Chem. 1923, 55, ${ }^{-605}$.

28. Michael, S. T. The relation of uric acid excretion to blood lactic acid in man. Amer. J. Physiol. 1944, $141,71$.

29. Yü, T. F., Sirota, J. H., Berger, L., Halpern, M., and Gutman, A. B. Effect of sodium lactate infusion on urate clearance in man. Proc. Soc. exp. Biol. (N. Y.) 1957, 96, 809.
30. Cori, C. F., and Cori, G. T. Glycogen formation in the liver from $d$ and $l$-lactic acid. J. biol. Chem. 1929, 81, 389.

31. Buchwald, K. W., Cori, C. F., and Fisher, R. E. The influence of $l$ - and $d$-lactate on oxygen consumption of rabbits. J. biol. Chem. 1933, 103, 763.

32. Eggleton, M. G. Urine acidity in alcohol diuresis in man. J. Physiol. 1946, 104, 312.

33. Barker, E. S., Elkinton, J. R., and Clark, J. K. Studies of the renal excretion of magnesium in man. J. clin. Invest. 1959, 38, 1733.

34. Gutman, A. B., and Yü, T. F. A three-component system for regulation of renal excretion of uric acid in man. Trans. Ass. Amer. Phycns 1961, 74, 353. 